Int. J. Electrochem. Sci., 11 (2016) $7282-7307$

\title{
Design, Spectroscopic Characterization, Electrical Conductivity and Molecular Modelling Studies of Biologically Puissant Co(II) and $\mathrm{Ni}$ (II) Complexes of $\mathrm{N}, \mathrm{N}^{\prime}$-bis(furan-2-ylmethyl)benzene-1,2- dicarboxamide
}

\author{
Katabathini Narasimharao ${ }^{1}$, Rayees Ahmad Shiekh ${ }^{2, *}$, Maqsood Ahmad Malik ${ }^{1, *}$, Musa A. Said ${ }^{2}$, \\ Zaheer Khan ${ }^{1}$, Shaeel Ahmed Al-Thabaiti ${ }^{1}$, Salman A. Khan ${ }^{1}$ \\ ${ }^{1}$ Chemistry Department, Faculty of Science, King Abdulaziz University, P.O. Box 80203, Jeddah \\ 21589, Saudi Arabia \\ ${ }^{2}$ Department of Chemistry, Faculty of Science, Taibah University, PO Box 30002, Almadinah \\ Almunawarrah, Saudi Arabia \\ *E-mail: rayeeschem@gmail.com, maqsoodchem@gmail.com
}

doi: $10.20964 / 2016.08 .43$

Received: 14 December 2015 / Accepted: 24 March 2016 / Published: 7 July 2016

A series of $\mathrm{N}, \mathrm{N}$-bis(furan-2-ylmethyl)benzene-1,2-dicarboxamide ligand (L) based metal complexes of general composition $\mathrm{M}\left(\mathrm{L}_{2}\right) \mathrm{X}_{2}$ [where $\mathrm{M}=\mathrm{Co}(\mathrm{II}), \mathrm{Ni}(\mathrm{II})$, and $\mathrm{L}=$ ligand and $\mathrm{X}=\mathrm{Cl}^{-}, \mathrm{CH}_{3} \mathrm{COO}^{-}$] were synthesized by conventional and microwave irradiation synthesis methods. Both ligand and its metal complexes were characterized by elemental analysis, molar conductance, NMR $\left({ }^{1} \mathrm{H}\right.$ and $\left.{ }^{13} \mathrm{C}\right)$, thermal analysis (TGA), infrared, UV-vis, mass spectral and molecular modelling studies. The elemental composition data revealed that the metal to ligand molar ration is 1:2 in all synthesized complexes. The obtained spectroscopy results for synthesized complexes indicated that the ligand behaved as a bidentate ligand and agreed well with the proposed structures. The solid state electrical conductivity of the complexes was studied as a function of temperature, indicating the semiconducting nature of the metal complexes. In order to evaluate the antimicrobial activity of metal ions upon chelation, the newly synthesized ligand and its metal complexes were tested for their antibacterial and antifungal activities by the disk diffusion method. The antioxidant activity of the representative complex was evaluated by using 1,1-diphenyl-2-picrylhydrazyl (DPPH) radical scavenging method. The antimicrobial and antioxidant activity results indicated that all metal complexes have been found to be more effective than the ligand as the process of chelation dominantly affects the overall biological behavior of the compounds.

Keywords: N,N'-bis(furan-2-ylmethyl)benzene-1,2-dicarboxamide; $\quad \mathrm{Co}(\mathrm{II}), \quad \mathrm{Ni}(\mathrm{II}) \quad$ complexes; Antimicrobial activities 


\section{FULL TEXT}

(C) 2016 The Authors. Published by ESG (www.electrochemsci.org). This article is an open access article distributed under the terms and conditions of the Creative Commons Attribution license (http://creativecommons.org/licenses/by/4.0/). 